\title{
Correlates of Quality of Life in New Migrants to Hong Kong from Mainland China
}

\author{
Winky K. F. Wong • Kee-Lee Chou • Nelson W. S. Chow
}

Accepted: 16 April 2011/ / Published online: 5 May 2011

(C) The Author(s) 2011. This article is published with open access at Springerlink.com

\begin{abstract}
The concept of Quality of life (QOL) has received considerable attention from different disciplines. The aim of this study was to identify what are the correlates of QOL among Chinese new immigrants in Hong Kong. Data were collected through a crosssectional survey among 449 Hong Kong new immigrants from Mainland China. Bivariate and multiple regression analyses were performed to examine the association between immigrants' QOL and their demographic characteristics, socio-economic factors, optimism, sense of control, perceived social support, perceived neighborhood disorder, collective efficacy, pre-migration planning, depressive symptoms and acculturation stress. Our findings demonstrated that depressive symptom is the most prominent factor in reducing immigrants' level of QOL, perceived social support and optimism are the two important factors that enhance the QOL of these depressed immigrants. Our results indicate that preventive measures must be developed, and professional counseling and psychological support services must be provided to new immigrants in Hong Kong, especially those who have depressive symptoms.
\end{abstract}

Keywords Quality of life · Depression · Immigrants · China · Hong Kong

\section{Introduction}

Although Hong Kong is part of China under the principle of "One Country, Two Systems", Mainland Chinese who want to live in Hong Kong need to apply for a visa, such as the Capital Investment Entrant Scheme (CIES), Admission Scheme for Mainland Talents and Professionals (ASMTP), and the Quality Migrant Admission Scheme (QMAS) which are aimed to attract talents and capital into Hong Kong, or the One-way Permit (OWP) which is designed for spouses and dependent children of Hong Kong permanent residents.

W. K. F. Wong $(\bowtie) \cdot$ K.-L. Chou · N. W. S. Chow

Department of Social Work and Social Administration, The University of Hong Kong,

Pokfulam Road, Hong Kong, China

e-mail: winky@graduate.hku.hk 
At present, a daily quota of 150 people from Mainland China with family ties in Hong Kong is granted an OWP to settle in Hong Kong.

These new immigrants from Mainland China have become the major source of population growth in Hong Kong. According to the Hong Kong Task Force on Population Policy which was published in 2003, from 1997 to 2001, new immigrants from Mainland China who were admitted under the One-way Permit Scheme were equivalent to some 93\% of the population growth in Hong Kong (HKSAR Government 2003). In the year of 2006, $3.2 \%$ of the total population were new immigrants who had resided in Hong Kong for less than 7 years (Census and Statistics Department 2006). It appears that this trend is expected to continue over the forecast period and Hong Kong will continue to rely on immigrants to maintain its population growth because the fertility rate in Hong Kong has been steadily decreased from 1.93 in 1981 to 1.04 in 2009 (Census and Statistics Department 2007; HKSAR Government 2010).

Studies revealed that these Chinese immigrants are facing serious difficulties in adjusting their lives in Hong Kong as they come to settle in this new society (Home Affairs Department and Immigration Department 2004, 2009; HKISS 1997; Mo et al. 2006; Lai 1997; Wong 2008; Chow and Ho 1996). These challenges, just to name a few, may include: unacceptable housing conditions, unemployment, low income, discrimination, social isolation, diminish of social and economic status, and in summary-poor quality of life. Thus, the situation of these new immigrants has gained tremendous attention and increasing studies are being conducted with the aim to help to facilitate a smooth adaptation process and to improve their quality of life.

\subsection{Quality of Life}

The concept of "quality of life" (QOL) is gaining increasing attentions; however, no consensus on its definition has been reached yet (Bayram et al. 2007; Chan et al. 2006). Nevertheless, there is a considerable agreement among researchers that the concept QOL is multi-dimensional (Bayram et al. 2007; Lowenstein and Katz 2005; Chan et al. 2006; Lim et al. 2008; van Servellen et al. 2002) which includes physical (individuals' perception of their physical state), psychological (individuals' perception of their cognitive and affective state) and social (individuals' perception of the interpersonal relationship and social roles in their life) dimensions (The WHOQOL Group 1995).

In addition, there is a growing recognition that QOL is subjective in nature (Lim et al. 2008; Lowenstein and Katz 2005; Vohra and Adair 2000) This "subjective" defining feature of QOL is in line with the definition put forwarded by the World Health Organization (1995) where QOL was defined as “individuals' perception of their position in life in the context of the culture and value systems in which they live and in relation to their goals, expectations, standards and concerns". In other word, QOL links with subjective well-being and represents an individual's overall satisfactions and happiness (Zhang et al. 2009; Vohra and Adair 2000).

\subsection{Quality of Life and Immigrants}

Undoubtedly, migrating to a new country is an extremely complex and stressful process because it involves changes in all areas of life-socially, culturally and psychologically (Benish-Weisman and Shye 2010). Although the underlying motive for most immigrants' emigration is to improve their QOL; migration is often associated with hardships, 
challenges, discriminations, economic difficulties and so forth. Thus, what are the determinants of immigrants' QOL? Increasing research is being conducted to address the question. Review of literatures indicate that immigrants' QOL is correlated with a wide range of individual's background characteristics, for example, age (Thoman and Surís 2004; Bayram et al. 2007; Pantzer et al. 2006), gender (Thoman and Surís 2004; Bayram et al. 2007; Zhang et al. 2009), marital status (Zhang et al. 2009; Bayram et al. 2007), education levels (van Servellen et al. 2002; Zhang et al. 2009), being at the low socioeconomic status (Pantzer et al. 2006; van Servellen et al. 2002; Thoman and Surís 2004) and psychosocial resources, such as perceived social support (Pantzer et al. 2006; Lim et al. 2008), optimism (O'Connell and Skevington 2005; Uskul and Greenglass 2005) and sense of control (Arruda et al. 1992; Kreitler et al. 2007; O'Connell and Skevington 2005).

In addition to the above mentioned individual's background characteristics, neighborhood living environment was found to be significantly correlated with QOL. Although the relationship between QOL and the perceived neighborhood disorder among immigrants has seldom been investigated, researches have indicated that perceived neighborhood disorder is one of the factors affecting the QOL among the general population (Ross et al. 2000; Woldoff 2002; Golub et al. 2003). When individuals living in a community where they perceived their neighborhoods are characterized by disorder, such as crimes, graffiti, danger or drugs, it would be expected that their QOL in the community would declines. On the other hand, having a greater social cohesion among neighbors and a high degree of residential stability would anticipate a positive impact on QOL, especially for immigrants who are not accustomed to the environment of their new society (Kooi and Patchin 2008).

Immigrants moving to a new society require a detailed planning, therefore, the degree of pre-migration planning was also found to affect their QOL in the new environment (Wang et al. 2010). In the study of 1,006 rural-to-urban migrants in China, Wang et al. (2010) found that preparation prior to migration was positively related to their coping skills which in turn has positive impacts on their QOL.

Apart from factors mentioned above, immigrants' psychological state was found to be another prominent factor in determining their level of QOL, for example, depression (Lim et al. 2008; Mui 1998) and the acculturation stress (Thoman and Surís 2004; van Servellen et al. 2002). These negative psychological states are to a great extent affected by their perceived social stigma and the discrimination experienced during their acculturation in the new society (Zhang et al. 2009; Gee and Ponce 2010; Pantzer et al. 2006; Wang et al. 2010).

Obviously, extensive research has been conducted in the Western context to investigate the determinants of immigrants' QOL and various aspects of their adaptation process. In Hong Kong, the focus lies mainly on the social and economic integration difficulties and service needs (HKISS 1997; So 2003; Wong 2008; Wong 2007; Lai 1997; The Hong Kong Council of Social Service 2009; Mo et al. 2006), the psychological well-being (Wong 2001; Lai 1997) and the employment situation (Lee 2004). In the area of QOL, studies could be found on economically disadvantaged group (Wong 2011, 2005), aged adult (Cheung et al. 2005; Lee 2005; Wong 2005; Chan et al. 2009), university students (Ng 2005), working adult (Cheung and Leung 2010; Mo and Mak 2010) and cancer patients (Lai et al. 2010).

Despite the evidence on the importance of QOL, and compare with the abundance of QOL research in the Western context, there is an obvious lack of studies in the Chinese context, adolescents and people experiencing economic disadvantage in particular (Shek 2010; Shek et al. 2005; Shek 2011) even though China has the largest population in the 
world. What's even worse, although there is continuing inflow of people migrating to Hong Kong from Mainland China and their QOL has become a significant concern, to the best of my knowledge, there is no study to investigate the correlates of QOL among these Chinese new immigrants in Hong Kong. Therefore, findings of the current study could serve as an addition to the existing literature.

Based on the extensive research on the correlates of immigrants' QOL in the Western context, we want to examine if these correlates apply to the Hong Kong context. This study attempted to test the hypothesis that immigrants' QOL is correlated with their sociodemographic characteristics, socio-economic status, psychosocial resources, perceived neighborhood disorder, collective efficacy, pre-migration planning, depressive symptoms and acculturation stress.

\section{Methodology}

\subsection{Sampling and Participants}

This study recruited adult immigrants who were (1) aged 18 or above, (2) came from Mainland China on a One-way Permit and plan to reside ordinarily in Hong Kong, (3) have resided in Hong Kong for at least 3 months but less than 6 months, and (4) migrated to Hong Kong for the purpose of family reunification. Because all new immigrants are required to apply for a Hong Kong Identity Card at the Registration of Persons-Kowloon Immigration Office within 30 days of their arrival to Hong Kong, using systematic random sampling method, our interviewers approached selected respondents at that immigration office and invited them to participate in the study. During the month of November 2006, 613 potential respondents were successfully recruited, but only 569 of them were found to be eligible respondents because some of them were too young. Out of these 569 eligible respondents, 501 agreed to participate in the study.

One of the inclusion criterions for our respondents in this study is that they must have resided in Hong Kong for at least 3 months, and almost all new immigrants apply for their Hong Kong Identity Card at the Kowloon Immigration Office in the first week following their arrival; therefore, we contacted these potential respondents 4 months later and conducted face-to-face interviews with them. During the 2-month period between March and April 2007, we successfully interviewed 449 respondents out of these 569 eligible respondents and yielding a response rate of $78.9 \%$.

\section{Measures}

\subsection{Quality of Life}

In this study, the dependent variable, QOL, was measured by the abbreviated version of the Hong Kong Chinese version of the World Health Organization Quality of Life (WHOQOL) Scale which has been previously validated in Hong Kong (Leung et al. 2005) and Taiwan (Yao et al. 2002) and has been widely used in Chinese population (Zhang et al. 2009; Wang et al. 2010; Chan et al. 2009, 2006). This abbreviated version WHOQOL is a self-report scale consisted of 28 items and the scale was found to have sound psychometric properties of reliability (Chan et al. 2006, 2009). Apart from the two general items, the other 26 items in the scale are grouped into four main domains including physical health 
(7 items), social relationship (3 items), psychological health (8 items) and environment (8 items). Participants were asked to rate themselves on a 5-point Likert scale ranging from 1 to 5 with a higher score indicating a better QOL. The possible raw scores for each domain are in the range from 7 to 35 for physical health, 3 to 15 for social relationship, and 8 to 40 for both psychological health and environment domains.

\subsection{Socio-demographic and Economic Variables}

Socio-demographic questions on immigrants' family background and personal characteristics were included in the study and these variables were controlled for in all data analyses in order to examine its correlation with their QOL. The demographic variables included immigrants' age, gender $(0=$ male, $1=$ female $)$, marital status $(1=$ single, $2=$ married, $3=\mathrm{divorced} / \mathrm{separated} /$ widowed), levels of formal education ( 5 levels, $1=$ no formal education, 2 = elementary school, 3 = junior high school, $4=$ senior high school, $5=$ college or above), monthly household income (13 levels, from $1=\mathrm{HK} \$ 1,999$ or less to $13=\mathrm{HK} \$ 30,000$ or above $)$, employment status $(0=$ unemployed, $1=$ employed, $)$ and if their family was receiving social welfare in Hong Kong i.e. Comprehensive Social Security Assistance (CSSA) $(0=$ no, $1=$ yes $)$.

\subsection{Optimism}

To assess the correlation between the disposition of optimism and the QOL, the revised Life Orientation Test (LOT-R) (Scheier et al. 1994; Scheier and Carver 1985) was adopted. This Chinese version LOT-R has been shown to have acceptable validity and reliability (Lai et al. 1998), and has been used in Chinese population (Lai and Yue 2000). This scale consists of 6 items and respondents were asked to indicate the extent to which they agreed or disagreed with 3 positively phrased items and 3 negatively phrased items on a 5-point scale, ranging from $1=$ strongly agree to $5=$ strongly disagree. The total scores were calculated by summing all items so that higher scores indicate more optimistic outlook on life.

\subsection{Sense of Control}

Sense of control was measured by a personal control scale developed by Mirowsky and Ross (1990). This instrument has high validity and test-retest reliability (Mirowsky and Ross 1990) and has been widely used in the studies of Chinese population (Chou and Chi 2001a, b). This scale consists of 8 items aimed at assessing respondents' perceived control and lack of control over good and bad outcomes. All of these 8 items were rated positive scores indicate a tendency to agree with internal statements and to disagree with external ones (negative scores indicate the opposite). Respondents were asked to what extent they agreed or disagreed with these 8 items on a 4-point scale, ranging from $1=$ strongly agree to $4=$ strongly disagree.

\subsection{Perceived Social Support}

The degree of perceived social support was measured using the Chinese version Multidimensional Scale of Perceived Social Support (MSPSS) developed by Zimet et al. (1988). This MSPSS has good internal and test-retest reliability as well as moderate construct validity (Zimet et al. 1988) and has been validated in Hong Kong (Chou 2000) and 
commonly used in Chinese populations (Short and Johnston 1997; Yu et al. 2004). This validated 12-item instrument was designed to assess perceptions of support from three distinct groups; family, friends and a significant other. Respondents were asked to rate on a 7-point Likert-type scale (from very strongly disagree to very strongly agree). Higher scores indicate greater perceived adequacy of social support.

\subsection{Perceived Neighborhood Disorder}

To measure the perceived neighborhood disorder, a 14-item scale which has high reliability and external validity developed by Ross and Mirowsky (1999) was adapted. This scale measures respondents' perceptions of both physical and social disorder within their neighborhood. Respondents were asked to indicate the degree to which each statement described how much they saw and experienced their neighborhood, with possible responses $1=$ strongly disagree to $4=$ strongly agree. Higher scores indicate more perceived neighborhood disorder.

\subsection{Collective Efficacy}

The collective efficacy was measured by the Collective Efficacy Scale developed by Sampson et al. (1997). This scale is one of the most widely used assessment tools in neighborhood research and has been used among Chinese immigrants population (Wu et al. 2010). This 10-item Likert-type scale aimed to measure respondents' perceptions of informal social control and social cohesion among neighborhood. Respondents were asked to respond to 2 aspects of statements. The first was how likely their neighbors could be counted on to respond to problems ( $1=$ very unlikely, $5=$ very likely) and the other was the extent to which they agreed with descriptions of the neighborhood $(1=$ strongly disagree, $5=$ strongly agree). Higher scores indicate a more social control, higher level of social cohesion and trust.

\subsection{Preparation for Migration}

To assess the preparation for migration, respondents were asked to answer eight questions which have been used in previous study (Ryan et al. 2006) and also in Chinese populations (Chou 2009). Although this scale has not been validated, these eight items were able to evaluate how well-prepared they were in migrating to Hong Kong, for examples, whether they had pre-arranged employment in Hong Kong, whether they had obtained family agreement with their decision and whether they had considered their length of stay. The extent of their preparation for migration was calculated as the sum of positive answers to the eight questions and higher scores indicate better prepared they were to migrate to Hong Kong.

\subsection{Depressive Symptoms}

To measure the severity of depressive symptoms, the self-reported 20-item Center for Epidemiologic Studies Depression (CES-D) Scale (Radloff 1977) was adopted. This Chinese version CES-D scale has been validated in Hong Kong (Chou and Chi 2000) and commonly used in Chinese populations (Chou and Chi 2000, 2001a; Pan et al. 2008). These 20 items are phrased as self-statements and respondents were asked to rate how 
frequently each item applied to them over the course of the past week using a 4-point scale ranging from $0=$ none, $1=1$ or 2 days a week, $2=3$ to 4 days per week and $3=5$ days or more per week. Scale scores were the unweighted sum of all items and higher scores indicate more severe depressive symptoms.

\subsection{Acculturation Stress}

The measure of acculturative stress in the social, attitudinal, familial, and environmental contexts was based on a standardized 26-item measure scale-Social, Attitudinal, Familial, and Environment (S.A.F.E.). This scale was developed by Hovey and Magana (2000) and has been commonly used among immigrants population (Fuertes and Westbrook 1996; Hovey and Magaña 2000) and in Chinese populations (Lee et al. 2000). This scale measures acculturation stress among immigrants in four dimensions: social, attitudinal, familial, and environmental. Respondents were asked to rate each item on a 6-point Likert scale, ranging from $0=$ no such experience, $1=$ not stressful to $5=$ extremely stressful. Higher scores indicate higher level of acculturation stress.

\subsection{Data Processing and Statistical Analysis}

Descriptive statistics of the frequencies, means and standard deviation of the variables in this study were first performed. Then the bivaritate correlations between QOL and all the independent variables were conducted. Afterward, we performed a multiple regression model in which the WHQOL was used as dependent variables while age, gender, marital status, education level, monthly household income, employment status, receiving social welfare, optimism, sense of control, perceived social support, perceived neighborhood disorder, collective efficacy, pre-migration planning, depressive symptoms and acculturation stress were entered as independent variables. In addition, four regression models were performed to examine the four different domains in the QOL measurement scale, including physical health, psychological health, social relationship, and environment with all independent variables. The data management and regression models were performed and computed with SPSS version 18.0 software package for window on PC. To adjust for multiple tests, the significance level for all tests was set at $P<0.01$ to reduce Type 1 error and increase the likelihood that the results will be replicated in future studies.

\section{Results}

\subsection{Characteristics of Study Sample}

The 449 new immigrants who participated in the current study were remarkably unevenly distributed with vast majority $(85.1 \%)$ were women and only $14.9 \%$ were men. In addition, about three quarters of them (76.1\%) fell into two age groups of 21-30 and 31-40 with the mean age of 34.6 and a standard deviation of 9.3 . The vast majority of them $(89.5 \%)$ were currently married and $6.9 \%$ were still single. $76.6 \%$ of the participants had completed high school education, with $40.5 \%$ had junior high school and $36.1 \%$ had senior high school. The median monthly household income range was in HK\$9,000 - 9,999, which was much lower than the median household income in Hong Kong of HK \$17,500 of the same year (Census and Statistics Department 2009). Majority of them (63.3\%) were unemployed and 
only $36.7 \%$ were currently being full-time or part-time employed. $13.4 \%$ of the respondents whose families were receiving the Comprehensive Social Security Assistance (CSSA). Frequency distributions, means, and standard deviations for all independent and dependent variables used in the multiple regression analyses are given in Table 1.

\subsection{Correlates of Quality of Life}

To identify the correlation between QOL with all independent variables, bivariate analysis was preformed. As shown in Table 2, the overall QOL was significantly related to immigrants' marital status, education levels, household income, social welfare status, optimism, perceived social support, perceived neighborhood disorder, collective efficacy, understanding of Hong Kong, pre-migration planning, depressive symptoms and acculturation stress.

To examine the correlates of overall QOL among new immigrants, a multiple regression model was performed with all independent variables. As shown in Table 3, perceived social support and optimism were found to be positively and significantly associated with the overall QOL, whereas the CES-D scores were found to be significantly associated, but negatively with the overall QOL.

The associations of the four domains of QOL with all independent variables were also examined. As shown in Table 3, the CES-D scores were found to be significantly and negatively correlated with the physical health domain while the perceived social support was found to be positively associated with this domain of QOL.

Same as the overall QOL, the psychological health domain was found to be associated with the perceived social support and optimism positively and significantly, whereas the CES-D scores were found to be associated significantly, but negatively with this domain.

Compared with results of the overall QOL, the social relationship domain has associations with lesser number of independent variables and it associated with perceived social support and the CES-D scores only.

On the contrary, the number of significant associations was greater for the environment domain than the overall QOL. Same as the overall QOL, it was significantly and positively associated with perceived social support, and optimism, but negatively related to the CESD scores. In addition, this domain was also negatively associated with the employment status (unemployed) and positively associated with household income.

\section{Discussion}

The aim of this study was to identify the correlates of QOL among Mainland Chinese new immigrants in Hong Kong by examining the association of QOL with their demographic characteristics, socio-economic factors, optimism, sense of control, perceived social support, perceived neighborhood disorder, collective efficacy, pre-migration planning, depressive symptoms and acculturation stress. Although there has been extensive research on various aspects of immigration process, the investigation on the determinants of immigrants' QOL in Hong Kong is yet to be addressed. Studying the determinants of QOL is important in order to understand and to improve the well-beings of this particular vulnerable group who migrate to a new society seeking for better QOL. In this study, we focus on the new immigrants in Hong Kong who migrated from Mainland China for the 
purpose of family reunion and has lived in Hong Kong for a short period of time-less than 6 months. The findings of this study may then contribute by filling the previously unexplored area.

Table 1 Descriptive statistics of socio-demographic and economic variables, CSSA receiving, HK's understanding, pre-migration planning, perceived neighborhood disorder, collective efficacy, CES-D, psycho-social variables acculturation stress and quality of life $(n=449)$

\begin{tabular}{|c|c|c|}
\hline Socio-demographic variables & $\begin{array}{l}\text { Percentage } \\
\text { (frequency) }\end{array}$ & Mean (SD) \\
\hline \multicolumn{3}{|l|}{ Gender } \\
\hline Males & $14.9 \%(67)$ & \\
\hline Female & $85.1 \%(382)$ & \\
\hline \multicolumn{3}{|l|}{ Marital status } \\
\hline Single & $6.9 \%(31)$ & \\
\hline Married & $89.5 \%(402)$ & \\
\hline Widowed/Separated/Divorced & $3.6 \%(16)$ & \\
\hline Age (range: 18-73) & & $34.6(9.3)$ \\
\hline $18-20$ & $3.3 \%(15)$ & \\
\hline $21-30$ & $34.5 \%(155)$ & \\
\hline $31-40$ & $41.6 \%(187)$ & \\
\hline $41-50$ & $14.5 \%(65)$ & \\
\hline $51-60$ & $2.9 \%(13)$ & \\
\hline 61 or above & $3.1 \%(14)$ & \\
\hline Education & & $3.4(0.9)$ \\
\hline No formal education & $2.7 \%(12)$ & \\
\hline Elementary school & $11.6 \%(52)$ & \\
\hline Junior high school & $40.5 \%(182)$ & \\
\hline Senior high school & $36.1 \%(162)$ & \\
\hline College or above & $9.1 \%(41)$ & \\
\hline
\end{tabular}

Household income in HK\$

$6.9(2.8)$

$\begin{array}{lc}1-3,999(1) & 4.5 \%(20) \\ 4,000-4,999(2) & 2.9 \%(13) \\ 5,000-5,999(3) & 6.9 \%(31) \\ 6,000-6,999(4) & 7.6 \%(34) \\ 7,000-7,999(5) & 8.7 \%(39) \\ 8,000-8,999(6) & 10.2 \%(46) \\ 9,000-9,999(7) & 13.8 \%(62) \\ 10,000-12,499(8) & 19.2 \%(86) \\ 12,500-14,999(9) & 7.1 \%(32) \\ 15,000-19,999(10) & 8.7 \%(39) \\ 20,000-24,999(11) & 6.9 \%(31) \\ 25,000-29,999(12) & 1.1 \%(5) \\ 30,000 \text { or above (13) } & 2.4 \%(11) \\ \text { Employment } & \\ \text { Employed } & 36.7 \%(165) \\ \text { Unemployed } & 63.3 \%(284) \\ \text { CSSA } & \end{array}$

Family members receiving CSSA

Not receiving CSSA
$13.4 \%(60)$

$86.6 \%$ (389) 
Table 1 continued

\begin{tabular}{lc}
\hline Socio-demographic variables & $\begin{array}{l}\text { Percentage } \\
\text { (frequency) }\end{array}$ \\
\hline Understanding of HK (range 1-4) & $0.9(0.6)$ \\
Pre-migration planning & $5.0(0.9)$ \\
Perceived neighborhood disorder & $28.1(3.7)$ \\
Collective efficacy & $34.8(4.3)$ \\
CES-D & $11.5(9.7)$ \\
Psycho-social variables & \\
Optimism & $19.1(2.2)$ \\
Sense of control & $20.4(2.2)$ \\
MSPSS & $56.6(17.5)$ \\
SAFE & $30.2(19.5)$ \\
Quality of life & $98.9(13.2)$ \\
Physical health domain & $21.8(2.6)$ \\
Psychological health domain & $27.6(4.1)$ \\
Social relationship domain & $10.7(1.7)$ \\
Environment domain & $24.9(4.9)$ \\
\hline
\end{tabular}

Table 2 Bivariate correlation coefficients for the relationship of independent variables $(n=449)$

\begin{tabular}{|c|c|c|c|c|c|}
\hline & $\begin{array}{l}\text { Overall } \\
\text { QOL } \\
\mathrm{r}\end{array}$ & $\begin{array}{l}\text { Physical } \\
\text { health } \\
\text { r }\end{array}$ & $\begin{array}{l}\text { Psychological } \\
\text { health } \\
\text { r }\end{array}$ & $\begin{array}{l}\text { Social } \\
\text { relationship } \\
\mathrm{r}\end{array}$ & $\begin{array}{l}\text { Environment } \\
\mathrm{r}\end{array}$ \\
\hline Gender $(0=$ male, $1=$ female $)$ & -.059 & -.072 & -.004 & .003 & .007 \\
\hline Marital status & $-.126^{* *}$ & -.071 & -.077 & -020 & -.084 \\
\hline Age & -.097 & -.022 & -.032 & -.063 & $-.142 * *$ \\
\hline Education (in 5 levels) & $.164 * * *$ & $.143 * *$ & $.144 * *$ & .106 & $.174 * * *$ \\
\hline Household income (in 13 levels) & $.278 * * *$ & .105 & $.202 * * *$ & $.153 * * *$ & $.286 * * *$ \\
\hline $\begin{array}{l}\text { Employment }(0=\text { unemployed, } \\
\quad 1=\text { employed })\end{array}$ & -.063 & -024 & -.035 & -.010 & $-.165 * * *$ \\
\hline $\begin{array}{l}\text { CSSA }(0=\text { not receiving, } \\
1=\text { receiving })\end{array}$ & $-.123 * *$ & .001 & -.110 & $-.156^{* * * *}$ & $-143 * *$ \\
\hline Understanding of $\mathrm{HK}$ & $.150 * * *$ & .101 & .083 & $.139 * *$ & $.182 * * *$ \\
\hline Pre-migration planning & $.210^{* * *}$ & $.202 * * *$ & .120 & $.162 * * *$ & $.206 * * *$ \\
\hline Collective efficacy & $.182 * * *$ & .093 & $.156^{* * * *}$ & $.180 * * *$ & .090 \\
\hline Perceived neighborhood disorder & $-.198 * * *$ & $-.146 * *$ & $-.140 * *$ & $-.157 * * *$ & $-.198 * * *$ \\
\hline SAFE & $-.423 * * *$ & $-.270 * * *$ & $-.307 * * *$ & $-.301 * * *$ & $-.370 * * *$ \\
\hline Sense of Control & .031 & .054 & .006 & -.025 & .082 \\
\hline MSPSS & $.458 * * *$ & $.277 * * *$ & $.410 * * *$ & $.520 * * *$ & $.402 * * *$ \\
\hline Optimism & $.463 * * *$ & $.202 * * *$ & $.364 * * *$ & $.285 * * *$ & $.381 * * *$ \\
\hline CES-D & $-.653 * * *$ & $-.366 * * *$ & $-.475 * * *$ & $-.434 * * *$ & $-.512 * * *$ \\
\hline
\end{tabular}

WHQOL quality of life scores

CSSA comprehensive social security assistance, SAFE social, attitudinal, familial and environmental acculturation stress scale, MSPSS Zimet's multidimensional scale of perceived social support, $C E S$ - $D$ Center for Epidemiologic Studies Depression Scale

** $P<0.01, * * * P<0.001$ 
Table 3 Standardized (Beta) regression coefficients for the relationship of independent variables $(n=449)$

\begin{tabular}{|c|c|c|c|c|c|}
\hline & $\begin{array}{l}\text { Overall } \\
\text { QOL } \\
\text { Beta }\end{array}$ & $\begin{array}{l}\text { Physical } \\
\text { health } \\
\text { Beta }\end{array}$ & $\begin{array}{l}\text { Psychological } \\
\text { health } \\
\text { Beta }\end{array}$ & $\begin{array}{l}\text { Social } \\
\text { relationship } \\
\text { Beta }\end{array}$ & $\begin{array}{l}\text { Environment } \\
\text { Beta }\end{array}$ \\
\hline Gender $(0=$ male, $1=$ female $)$ & -.029 & -.024 & .046 & .035 & -.002 \\
\hline Marital status & .043 & .001 & .034 & .097 & .073 \\
\hline Age & -.054 & .011 & .029 & -.022 & -.072 \\
\hline Education (in 5 levels) & .085 & .104 & .101 & .034 & .091 \\
\hline Household income (in 13 levels) & .072 & -.012 & .042 & -.040 & $.114 * *$ \\
\hline $\begin{array}{l}\text { Employment }(0=\text { unemployed, } \\
\quad 1=\text { employed })\end{array}$ & -.059 & -.007 & -.026 & .025 & $-.160 * * *$ \\
\hline $\begin{array}{l}\text { CSSA }(0=\text { not receiving, } \\
1=\text { receiving })\end{array}$ & -.009 & .057 & -.014 & -.077 & -.033 \\
\hline Understanding of HK & -.051 & -.043 & -.061 & -.006 & .006 \\
\hline Pre-migration planning & .022 & .105 & -.011 & .044 & .037 \\
\hline Collective efficacy & .043 & -.009 & .045 & .041 & -.036 \\
\hline Perceived neighborhood disorder & -.048 & -.073 & -.015 & -.033 & -.080 \\
\hline SAFE & -.090 & -.086 & -.069 & -.063 & -.085 \\
\hline Sense of control & -.056 & -.006 & -.044 & -.059 & -.003 \\
\hline MSPSS & $.177^{* * *}$ & $.148 * *$ & $.220 * * *$ & $.379 * * *$ & $.169^{* * *}$ \\
\hline Optimism & $.206^{* * * *}$ & .042 & $.171 * * *$ & .080 & $.177 * * *$ \\
\hline CES-D & $-.429 * * *$ & $-.217 * * *$ & $-.290 * * *$ & $-.236 * * *$ & $-.283 * * *$ \\
\hline
\end{tabular}

WHQOL quality of life scores

CSSA comprehensive social security assistance, SAFE social, attitudinal, familial and environmental acculturation stress scale, MSPSS Zimet's multidimensional scale of perceived social support, CES-D Center for Epidemiologic Studies Depression Scale

$* * P<0.01, * * * P<0.001$

Findings of the current study provide important information about the correlates of QOL among Chinese new immigrants in Hong Kong. Results of both bivariate and regression analyses demonstrate that depressive symptoms have the strongest association with all the four domains of QOL among all the independent variables we measured in this study. Migrating to a new society is a stressful life transition for anyone, and depressive symptoms have been commonly found on new immigrants and our findings indicate that these depressive symptoms have a substantial impact on every domains of their QOL. Fortunately, previous study shown that the severity of depressive symptoms among new immigrants did not remain for a long period, in fact, decrease with time (Miszkurka et al. 2010). Therefore, this finding suggests that depressive symptoms need to be addressed aggressively in order to enhance the QOL of these new-comers, especially during the first 6 months of their arrival in Hong Kong.

Although the prevalence of depressive symptoms has significant negative impacts on immigrants' QOL, the findings of both bivariate and regression analyses highlight a significant variable which can enhance every domains of the QOL of these depressed immigrants - the perceived social support. That is, when immigrants are confronted with depression, the perceived availability of social support helps to reduce the severity of their depressive symptoms. In fact, the positive effects of perceived social support on immigrants' psychological health have been well-documented (Chou 2009; Kuo and Tsai 1986; 
Remennick 2005). This belief of supportive behaviors is available when needed is able to help the stressor to re-evaluate the potential threats and can boost his or her ability to cope or to alter their physiological or behavioral response (Cohen et al. 2000). Therefore, an effective intervention designed to increase immigrants' perceived social support could potentially help to enhance their QOL and to improve the severity of their depressive symptoms.

Our findings also revealed that the optimistic disposition is another positive variable which could enhance immigrants' QOL, especially in the psychological health and environment domains. An optimistic person is someone who would see things in a more positive way, is more optimistic about the future and typically handle stressful events in a more active coping strategies (Uskul and Greenglass 2005; Shelby et al. 2008; Dougall et al. 2001; Brissette et al. 2002) and extensive studies have demonstrated that optimism was significantly and negatively related to depressive symptoms (Ekas et al. 2010; Uskul and Greenglass 2005; Scheier et al. 1994). That is, individuals who have high levels of optimism are less likely to develop depressive symptoms. In other words, optimism could reduce depressive symptoms which in turn contribute to enhance immigrant's QOL.

Besides, it was interesting to find that higher level of QOL associates with only the optimism and perceived social support components of the psychosocial resources and no association was found between QOL and sense of control in both bivariate and multiple regression analyses. Given the fact that there has been extremely scarce research in the relationship between sense of control and QOL among immigrant population, therefore, we searched for similar studies as alternative references. We found that sense of mastery has the greatest direct effect on the QOL among patients with schizophrenia in Taiwan (Hsiung et al. 2010), was an important predictor of QOL among Chinese gynecologic cancer survivors (Lai et al. 2010) and was the most important factor related to life satisfaction among adolescents from immigrant families in Portugal (Neto 2001). Since personal control is one of the important psychological resources which plays a substantial role in the stress coping process (Lai et al. 2010), and therefore, future research in the association between QOL and sense of control on immigrant population is highly recommended.

Though previous studies have reported the correlations of immigrants' age, sex and marital status with their QOL (Thoman and Surís 2004; Bayram et al. 2007; Pantzer et al. 2006; Zhang et al. 2009) in both bivariate and multiple regression analyses, however, these correlations were not observed in this study. Although correlation was found between immigrants' age and the environment domain of QOL, and between marital status with the overall QOL in bivariate analyses, these associations disappeared in the multiple regression analysis due to the crowding out effects. Obviously, the current study revealed that the effects of age, sex and marital status on immigrants' QOL were not significant. The possible explanation for the discrepancy of our findings with the previous studies may be due to the sample issue where $76.1 \%$ of the respondents in this study fall in the age range between 21 and 40 and substantial majority of them (85.1\%) were female. Most interestingly, it is expected that those who are married would have higher QOL, especially in the social relationship domain as previous studies have suggested that being married was often associated with larger social networks and more social relationship (Cornman et al. 2001; Liebler and Sandefur 2002; Turner and Marino 1994) because additional social network linkages from the spouse have been added. However, about $10 \%$ of the respondents in the present study were currently single, and therefore, no significant association between marital status and the social relationship domain of QOL was found in both bivariate and multiple regression analyses. Nevertheless, this finding could be an important 
reflection of the unfavorable social relation situation of new immigrants; especially those who have resided in Hong Kong for less than 6 months.

While findings of the current study did not reveal significant correlations of demographic characteristics with QOL in both bivariate and multiple regression analyses, it indicated that education attainment and household income were positively associated with immigrants' QOL. In addition, employment status (unemployed) was also found to be associated with the environment domain negatively in both bivariate and multiple regression analysis. Although the significant association between education attainment and household income with overall QOL disappeared in multiple regression analysis due to the crowding out effects, results revealed the importance of the economic determinants on immigrants' QOL. From an economic perspective, it is assumed that those who are at lower economic status are often in disadvantaged positions and are often at a greater risk of having poorer QOL. In other words, education can contribute to the increasing of an individual's earning capacity and eventually help to enhance his or her QOL. Interestingly, our findings did not show the association between immigrants' social welfare status and their QOL in multiple regression analysis. This could only be explained by the confounding factor that only $13.4 \%$ of the immigrants in the study have family members receiving social welfare (Comprehensive Social Security Assistance) in Hong Kong.

It would be expected that if immigrants could have an adequate planning and a thorough understanding of the destination country before moving permanently, it could help to facilitate a smooth transition process and will ultimately exert a better QOL. However, findings of the multiple regression analysis did not show significant associations between the understandings of Hong Kong and the quality of the pre-migration planning with immigrants' QOL. Interestingly, not only these pre-migration factors did not exhibit pronounced significant associations with immigrants' QOL, but also the post-migration factors. The collective efficacy, perceived neighborhood disorder and acculturation stress did not exhibit association with any domain of QOL at all. The lack of statistically significant association between these pre- and post- migration factors with QOL could be explained by the crowding out effects. While many variables are bivariately correlated with immigrants' QOL, the effects disappear in multiple regression analysis that includes other variables.

We also explored in the present study the mediating effect of depressive symptoms on the relationship between acculturation stress and immigrants' QOL. To test the hypothesized mediating effects, a series of multiple regression analyses were performed after controlling for all variables in the model in accordance with the model proposed by (Baron and Kenny 1986). In the initial step, regression analyses were performed to determine if there was a significant relationship between acculturation stress and immigrants' QOL. In the second step of analyses, we examined if there was a significant association between acculturation stress and depressive symptoms; in the third step, we tested if there was a significant association between the depressive symptoms and immigrants' QOL after controlling for acculturation stress. Finally, after these relationship had been established, the significance of the indirect effect of the acculturation stress on the QOL via the depressive symptoms was tested using the Sobel's (1982) test.

It has been well-documented that acculturation stress has a significant influence on the QOL among new immigrants (Thoman and Surís 2004; van Servellen et al. 2002) and this statistically significant effect was observed in the current study before the introduction of the proposed mediator $(B=-.265 ; P<.001)$. That is, when individuals experience higher levels of acculturation stress, every domains of their QOL suffered. However, after introducing the mediating variable, the depressive symptoms, the effects of acculturation stress on immigrants' overall QOL disappeared $(B=-.090 ; P=.026)$. In fact, this fully 
mediating effect applied on every domains of QOL. The Sobel test also indicated that the mediating effect of depressive symptoms on immigrants' overall QOL was significant $(z=-7.182 ; P<.001)$. In other words, the mechanism as to how acculturation stress is related to immigrants' QOL appears to be very straightforward, depressive symptoms fully mediated the relationship between acculturation stress and every domains of QOL. Specifically, the relationship between acculturation stress and QOL can be described exclusively in terms of the indirect effects of depressive symptoms. This finding suggested that if immigrants' depressive symptoms could be alleviated, their QOL may also be improved regardless of the severity of acculturation stress. If this meditational relationship does exist, interventions that focus on alleviating depressive symptoms rather than acculturation stress may be more effective in improving the QOL of this vulnerable group.

\section{Limitations}

While the present study sheds light on the correlates of QOL among Chinese immigrants in Hong Kong, it is important to acknowledge its methodological limitations that restrict generalization of these results. Firstly, this cross-sectional study was unable to reflect the changes in QOL and other variables; and therefore it could not evaluate the causal associations among the above mentioned variables. Secondly, although this study involved a wide range of variables that had been previously found to be associated with QOL, there are other potentially important factors that have not included in this study. For example, the present study did not address the perceived discrimination, immigrants' health status, expectation-reality discrepancy and coping skills. Thirdly, the measure of depression in this study was based on a self-report questionnaire assessing immigrants' current depressive symptoms. Since it was not based on expert-administered diagnostic interviews and clinical assessments, and the results may not show the accurate clinical information. Therefore, our results could not be generalized to the clinical diagnosis of depression. Lastly but not the least, despite efforts to ensure the representativeness of the samples, our study samples were predominantly married $(89.5 \%)$ female $(85.1 \%)$. It was not a surprise to find the uneven distribution of respondents in our samples because according to the government's statistics, between the years of 1998 and 2009, a total number of 592,000 new immigrants have immigrated to Hong Kong on the One-way Permit, in which an average of $69.1 \%$ was female and among these newly arrived female immigrants, $70.6 \%$ were aged 25 or above who were typically spouses of Hong Kong permanent residents men (Home Affairs Department and Immigration Department 2004, 2009). Although our study samples reflect the real gender and marital status distribution of the immigrant population, the result of this study cannot be generalized to male immigrants, as well as single and married Chinese immigrants in Hong Kong. Since previous studies found that marital status associated with immigrants' QOL (Zhang et al. 2009; Bayram et al. 2007), and QOL of male immigrants was found to be higher than that of females (Bayram et al. 2007), therefore, studies of male immigrants and single Chinese new immigrants in Hong Kong must be conducted in the future so that these issues can be addressed.

\section{Conclusion}

Even with these limitations, our findings revealed useful information about the determinants of QOL among new immigrants from Mainland China to Hong Kong. In summary, 
the important determinants of a good QOL among new immigrants are less depression, optimistic personality, high level of perceived social support and high socio-economic status. Clearly, the negative impacts of depressive symptoms and the positive effects of perceived social support and optimism on QOL prevailed among new immigrants who have stayed in Hong Kong for 6 months. However, these negative impact of depressive symptoms and the positive effects of perceived social support and optimism on QOL may be significant but were transient, because our sample of immigrants have not stayed in Hong Kong long enough to examine the effect of these variables on their QOL over time. Therefore, in the future, longitudinal study should be conducted to investigate the ways in which these variables changes over time. In addition, recommendations for further research should include exploration of variables that will further explain the variance of quality of life and sampling that reflects male population and marital status.

\section{Implications}

Clearly, improving the QOL among new immigrants is a complicated and difficult task. This study has identified the determinants of QOL among this specific vulnerable group in the society and it is important to understand the factors affecting immigrants' QOL in order to assess, manipulate, or intervene the appropriate kind of social policy for this vulnerable population group. Findings of the present study have some significant implications for intervention and health promotion programs to improve immigrants' QOL. The mental health of Chinese new immigrants has become an increasing concern; results of this study indicate that depression, lack of perceived social support and low socio-economic status were significantly associated with poor QOL. Therefore, in order to improve immigrant's QOL, quality and affordable professional counseling and psychological support services should be provided to new immigrants, especially those who have depressive symptoms. In addition, our findings also suggested that an enhancement of perceived social support might also be an effective factor to improve immigrants' QOL. Lastly, in order to improve immigrants' socio-economic status, the government needs to implement a comprehensive policy to provide adequate education opportunities for immigrants so that they can acquire the necessary knowledge and capacity to create their own future. In addition, social interventions or programs should be packaged to enhance the employment opportunities for new immigrants and it is worth the price because having stable income is one of the most important elements to improve immigrant's QOL.

Acknowledgments Grant sponsor: This work was funded by the Research Grant Council, Public Policy Research Funding Scheme (HKU 7004-PPR20051).

Open Access This article is distributed under the terms of the Creative Commons Attribution Noncommercial License which permits any noncommercial use, distribution, and reproduction in any medium, provided the original author(s) and source are credited.

\section{References}

Arruda, E. N., Larson, P. J., \& Meleis, A. I. (1992). Immigrant hispanic cancer patients' views. Cancer Nursing, 15(6), 387-394.

Baron, R. M., \& Kenny, D. A. (1986). The moderator-mediator variable distinction in social psychological research: Conceptual, strategic, and statistical considerations. Journal of Personality and Social Psychology, 51(6), 1173-1182. 
Bayram, N., Thorburn, D., Demirhan, H., \& Bilgel, N. (2007). Quality of life among Turkish immigrants in Sweden. Quality of Life Research, 16(8), 1319-1333.

Benish-Weisman, M., \& Shye, S. (2010). Life quality of Russian immigrants to Israel: Patterns of success and of unsuccess. Social Indicators Research, Published online.

Brissette, I., Scheier, M. F., \& Carver, C. S. (2002). The role of optimism in social network development, coping, and psychological adjustment during a life transition. Journal of Personality and Social Psychology, 82(1), 102-111.

Census and Statistics Department. (2006). 2006 population by-census: Thematic report-persons from the Mainland having resided in Hong Kong for less than 7 years. Hong Kong: Hong Kong SAR Government.

Census and Statistics Department. (2007). Hong Kong monthly digest of statistics: The fertility trend in Hong Kong, 1981 to 2006. Hong Kong.

Census and Statistics Department. (2009). Hong Kong annual digest of statistics. Hong Kong, SAR: Census and Statistics Department.

Chan, W. C. S., Chiu, F. K. H., Chien, W. T., Thompson, D., \& Lam, L. (2006). Quality of life in Chinese elderly people with depression. International Journal of Geriatric Psychiatry, 21(4), 312-318.

Chan, W. C. S., Chiu, F. K. H., Chien, W. T., Goggins, W., Thompson, D., \& Hong, B. (2009). Predictors of change in health-related quality of life among older people with depression: A longitudinal study. International Psychogeriatrics, 21(6), 1171-1179.

Cheung, C. K., \& Leung, K. (2010). Ways that social change predicts personal quality of life. Social Indicators Research, 96(3), 459-477.

Cheung, J. K., Kwan, A. H., Chan, S. C., Ngan, R. H., Ng, S., Leung, E. F., et al. (2005). Quality of life in older adults: Benefits from caring services in Hong Kong. Social Indicators Research, 71(1-3), 291-334.

Chou, K. L. (2000). Assessing Chinese adolescents' social support: The multidimensional scale of perceived social support. Personality and Individual Differences, 28(2), 299-307.

Chou, K. L. (2009). Pre-migration planning and depression among new migrants to Hong Kong: The moderating role of social support. Journal of Affective Disorders, 114(1), 85-93.

Chou, K. L., \& Chi, I. (2000). Stressful events and depressive symptoms among old women and men: A longitudinal study. The International Journal of Aging and Human Development, 51(4), 275-293.

Chou, K. L., \& Chi, I. (2001a). Social support exchange among elderly Chinese people and their family members in Hong Kong: A longitudinal study. International Journal of Aging and Human Development, 53(4), 275-291.

Chou, K. L., \& Chi, I. (2001b). Stressful life events and depressive symptoms: Social support and sense of control as mediators or moderators? International Journal of Aging and Human Development, 52(2), $155-171$.

Chow, N. W. S., \& Ho, J. K. M. (1996). Social work with new arrivals. In I. Chi \& S. K. Cheung (Eds.), Social work in Hong Kong. Hong Kong: Hong Kong Social Workers Association.

Cohen, S., Gottlieb, B. H., \& Underwood, L. G. (2000). Social relationship and health. In S. Cohen, L. G. Underwood, \& B. H. Gottlieb (Eds.), Social support measurement and intervention: A guide for health and social scientists. New York: Oxford University Press.

Cornman, J. C., Goldman, N., Weinstein, M., \& Lin, H. S. (2001). Perception of elderly Taiwanese about the availability of social support (pp. 1-42). Princeton, NJ: Office of Population Research Princeton University.

Dougall, A. L., Hyman, K. B., Hayward, M. C., McFeeley, S., \& Baum, A. (2001). Optimism and traumatic stress: The importance of social support and coping. Journal of Applied Social Psychology, 31(2), 223245 .

Ekas, N. V., Lickenbrock, D. M., \& Whitman, T. L. (2010). Optimism, social support, and well-being in mothers of children with autism spectrum disorder. Journal of Autism and Developmental Disorders, 40 (10), 1274-1284.

Fuertes, J. N., \& Westbrook, F. D. (1996). Using the social, attitudinal, familial, and environmental (S.A.F. E.) acculturation stress scale to assess the adjustment needs of hispanic college students. Measurement and Evaluation in Counseling and Development, 29(2), 67-76.

Gee, G. C., \& Ponce, N. (2010). Associations between racial discrimination, limited English proficiency, and health-related quality of life among 6 Asian ethnic groups in California. American Journal of Public Health, 100(5), 888-895.

Golub, A., Johnson, B. D., Taylor, A., \& Eterno, J. (2003). Quality-of-life policing: Do offenders get the message? Policing: An International Journal of Police Strategies and Management, 26(4), 690-707.

HKISS. (1997). A study on the Chinese new immigrants in Hong Kong. Hong Kong: International Social Service. 
HKSAR Government. (2003). Task force on population policy. Hong Kong: HKSAR Government.

HKSAR Government. (2010). Hong Kong: The facts. Hong Kong: The Information Services Department.

Home Affairs Department and Immigration Department. (2004). Statistics on new arrivals from the mainland. Hong Kong: HK SAR Government.

Home Affairs Department and Immigration Department. (2009). Statistics on new arrivals from the mainland. Hong Kong: HK SAR Government.

Hovey, J. D., \& Magaña, C. (2000). Acculturative stress, anxiety, and depression among Mexican immigrant farm workers in the Midwest United States. Journal of Immigrant Health, 2(3), 119-131.

Hsiung, P. C., Pan, A. W., Liu, S. K., Chen, S. C., Peng, S. Y., \& Chung, L. (2010). Mastery and stigma in predicting the subjective quality of life of patients with schizophrenia in Taiwan. Journal of Nervous and Mental Disease, 198(7), 494-500.

Kooi, B. R., \& Patchin, J. W. (2008). Neighborhood disadvantage in a moderately sized city: A SEM analysis. Criminal Justice Studies, 21(4), 325-340.

Kreitler, S., Peleg, D., \& Ehrenfeld, M. (2007). Stress, self-efficacy and quality of life in cancer patients. Psychooncology, 16(4), 329-341.

Kuo, W. H., \& Tsai, Y. M. (1986). Social networking, hardiness and immigrant's mental health. Journal of Health and Social Behavior, 27(1), 133-149.

Lai, P. C. Y. (1997). An exploratory study on Chinese immigrant women in Hong Kong. In D. T. L. Shek, M. C. Lam, \& C. F. Au (Eds.), Social work in Hong Kong: Reflections and challenges. Hong Kong: The Chinese University of Hong Kong.

Lai, J. C. L., \& Yue, X. (2000). Measuring optimism in Hong Kong and Mainland Chinese with the revised life orientation test. Personality and Individual Differences, 28(4), 781-796.

Lai, J. C. L., Cheung, H., Lee, W. M., \& Yu, H. (1998). The utility of the revised life orientation test to measure optimism among Hong Kong Chinese. International Journal of Psychology, 33(1), 45-56.

Lai, B. P. Y., Tang, C. S. K., \& Chung, T. K. H. (2010). A prospective longitudinal study investigating neuroticism and mastery as predictors of quality of life among Chinese gynecologic cancer survivors. Quality of Life Research, 19(7), 931-941.

Lee, K. M. W. (2004). Ethnic and gender relations in Hong Kong: The work experiences of recent Mainland Chinese immigrant women. Asian and Pacific Migration Journal, 13(2), 233-253.

Lee, J. L. (2005). An exploratory study on the quality of life of older Chinese people living alone in Hong Kong. Social Indicators Research, 71(1-3), 335-361.

Lee, R. M., Choe, J., Kim, G., \& Ngo, V. (2000). Construction of the Asian American family conflicts scale. Journal of Counseling Psychology, 47(2), 211-222.

Leung, K. F., Wong, W. W., Tay, M. S. M., Chu, M. M. L., \& Ng, S. S. W. (2005). Development and validation of the interview version of the Hong Kong Chinese WHOQOL-BREF. Quality of Life Research, 14(5), 1413-1419.

Liebler, C. A., \& Sandefur, G. D. (2002). Gender differences in the exchange of social support with friends, neighbors, and co-workers at midlife. Social Science Research, 31(3), 364-391.

Lim, J., Yi, J., \& Zebrack, B. (2008). Acculturation, social support, and quality of life for Korean immigrant beast and gynecological cancer survivors. Ethnicity and Health, 13(3), 243-260.

Lowenstein, A., \& Katz, R. (2005). Living arrangements, family solidarity and life satisfaction of two generations of immigrants in Israel. Ageing \& Society, 25(5), 749-767.

Mirowsky, J., \& Ross, C. E. (1990). Control or defense? Depression and the sense of control over good and bad outcomes. Journal of Health and Social Behavior, 31(1), 71-86.

Miszkurka, M., Goulet, L., \& Zunzunegui, M. V. (2010). Contributions of immigration to depressive symptoms among pregnant women in Canada. Canadian Journal of Public Health, 101(5), 358-364.

Mo, P. K. H., \& Mak, W. S. (2010). The influence of health promoting practices on the quality of life of community adults in Hong Kong. Social Indicators Research, 95(3), 503-517.

Mo, P. K. H., Mak, W. W. S., \& Kwan, C. S. Y. (2006). Cultural change and Chinese immigrants' distress and help-seeking in Hong Kong. Journal of Ethnic \& Cultural Diversity in Social Work, 15(3/4), $129-151$.

Mui, A. C. (1998). Living alone and depression among older Chinese immigrants. Journal of Gerontological Social Work, 30(33), 147-166.

Neto, F. (2001). Satisfaction with life among adolescents from immigrant families in Portugal. Journal of Youth and Adolescence, 30(1), 53-67.

$\mathrm{Ng}$, S. L. (2005). Subjective residential environment and its implications for quality of life among university students in Hong Kong. Social Indicators Research, 71(1-3), 467-489.

O'Connell, K. A., \& Skevington, S. M. (2005). The relevance of spirituality, religion and personal beliefs to health-related quality of life: Themes from focus groups in Britain. British Journal of Health Psychology, 10(3), 379-398. 
Pan, A., Franco, O. H., Wang, Y. F., Yu, Z. J., Ye, X. W., \& Lin, X. (2008). Prevalence and geographic disparity of depressive symptoms among middle-aged and elderly in China. Journal of Affective Disorders, 105(1-3), 167-175.

Pantzer, K., Rajmil, L., Tebé, C., Codina, F., Serra-Sutton, V., Ferrer, M., et al. (2006). Health related quality of life in immigrants and native school aged adolescents in Spain. Journal of Epidemiology and Community Health, 60(8), 694-698.

Radloff, L. S. (1977). The ces-d scale: A self-report depression scale for research in the general population. Applied Psychological Measurement, 1(3), 385-401.

Remennick, L. (2005). Immigration, gender, and psychosocial adjustment: A study of 150 immigrant couples in Israel. Sex Roles, 53(11-12), 847-863.

Ross, C. E., \& Mirowsky, J. (1999). Disorder and decay: The concept and measurement of perceived neighborhood disorder. Urban Affairs Review, 34(3), 412-432.

Ross, C. E., Reynolds, J. R., \& Geis, K. J. (2000). The contingent meaning of neighborhood stability for residents' psychological well-being. American Sociological Review, 65(4), 581-597.

Ryan, L., Leavey, G., Golden, A., Blizard, R., \& King, M. (2006). Depression in Irish migrants living in London: Case-control study. British Journal of Psychiatry, 188(6), 560-566.

Sampson, R. J., Raudenbush, S. W., \& Earls, F. (1997). Neighborhoods and violent crime: A multilevel study of collective efficacy. Science, 277(5328), 918-924.

Scheier, M. F., \& Carver, C. S. (1985). Optimism, coping, and health: Assessment and implications of generalized outcome expectancies. Health Psychology, 4(3), 219-247.

Scheier, M. F., Carver, C. S., \& Bridges, M. W. (1994). Distinguishing optimism from neuroticism (and trait anxiety, self-mastery, and self-esteem): A reevaluation of the life orientation test. Journal of Personality and Social Psychology, 67(6), 1063-1078.

Shek, D. T. L. (2010). Introduction: Quality of life of Chinese people in a changing world. Social Indicators Research, 95(3), 357-361.

Shek, D. T. L. (2011). Quality of life research: Responses to emerging issues in a changing world. Social Indicators Research, 100, 371-374.

Shek, D. T. L., Chan, Y. K., \& Lee, P. S. N. (2005). Quality of life in the global context: A Chinese response. Social Indicators Research, 71(1-3), 1-10.

Shelby, R. A., Crespin, T. R., Wells-Di Gregorio, S. M., Lamdan, R. M., Siegel, J. E., \& Taylor, K. L. (2008). Optimism, social support, and adjustment in African American women with breast cancer. Journal of Behavioral Medicine, 31(5), 433-444.

Short, K. H., \& Johnston, C. (1997). Stress, maternal distress, and children's adjustment following immigration: The buffering role of social support. Journal of Consulting and Clinical Psychology, 65(3), 494-503.

So, A. Y. (2003). Cross-border families in Hong Kong: The role of social class and politics. Critical Asian Studies, 35(4), 515-534.

Sobel, M. E. (1982). Asymptotic confidence intervals for indirect effects in structural equations models. In S. Leinhart (Ed.), Sociological methodology. San Francisco: Jossey-Bass.

The Hong Kong Council of Social Service. (2009). Report on cross-border family (跨境家庭生活現沉及來 港生活計劃研究報告). Hong Kong: The Hong Kong Council of Social Service.

The WHOQOL Group. (1995). The world health organization quality of life assessment (WHOQOL): Position paper from the World Health Organization. Social Science \& Medicine, 41(10), 1403-1409.

Thoman, L. V., \& Surís, A. (2004). Acculturation and acculturative stress as predictors of psychological distress and quality-of-life functioning in Hispanic psychiatric patients. Hispanic Journal of Behavioral Sciences, 26(3), 293-311.

Turner, R. J., \& Marino, F. (1994). Social support and social structure: A descriptive epidemiology. Journal of Health and Social Behavior, 35(3), 193-212.

Uskul, A. K., \& Greenglass, E. (2005). Psychological wellbeing in a Turkish -Canadian sample. Anxiety, Stress, and Coping, 18(3), 269-278.

van Servellen, G., Chang, B., \& Lombardi, E. (2002). Acculturation, socioeconomic vulnerability, and quality of life in Spanish-speaking and bilingual Llatino HIV-infected men and women. Western Journal of Nursing Research, 24(3), 246-263.

Vohra, N., \& Adair, J. (2000). Life satisfaction of Indian immigrants in Canada. Psychology and Developing Societies, 12(2), 109-138.

Wang, B., Li, X. M., Stanton, B., \& Fang, X. Y. (2010). The influence of social stigma and discriminatory experience on psychological distress and quality of life among rural-to-urban migrants in China. Social Science and Medicine, 71(1), 84-92.

Woldoff, R. A. (2002). The effects of local stressors on neighborhood attachment. Social Forces, 81(1), $87-116$. 
Wong, D. F. K. (2001). Differential functions and sources of social support of Mainland Chinese immigrants during resettlement in Hong Kong: A qualitative analysis. Journal of Social Work Research, 2(2), 319-332.

Wong, H. (2005). The quality of life of Hong Kong's poor households in the 1990s: Levels of expenditure, income security and poverty. Social Indicators Research, 71(1-3), 411-440.

Wong, S. (2007). Exploring 'unseen' social capital in community participation: Everyday lives of poor Mainland Chinese migrants in Hong Kong. Amsterdam: Amsterdam University Press.

Wong, D. F. K. (2008). Differential impacts of stressful life events and social support on the mental health of Mainland Chinese immigrant and local youth in Hong Kong: A resilience perspective. British Journal of Social Work, 38(2), 236-252.

Wong, H. (2011). Quality of life of poor people living in remote areas in Hong Kong. Social Indicators Research, 100(3), 435-450.

Wu, Q. B., Palinkas, L. A., \& He, X. S. (2010). An ecological examination of social capital effects on the academic achievement of Chinese migrant children. British Journal of Social Work, published April, 14 (2010), 1-20.

Yao, G., Chung, C. W., Yu, C. F., \& Wang, J. D. (2002). Development and verification of validity and reliability of the WHOQOL-BREF Taiwan version. Journal of the Formosan Medical Association, 101 (5), 342-351.

Yu, D. S. F., Lee, D. T. F., \& Woo, J. (2004). Psychometric testing of the Chinese version of the medical outcomes study social support survey (mos-sss-c). Research in Nursing and Health, 27(2), 135-143.

Zhang, J., Li, X. M., Fang, X. Y., \& Xiong, Q. (2009). Discrimination experience and quality of life among rural-to-urban migrants in China: The mediation effect of expectation-reality discrepancy. Quality of Life Research, 18(3), 291-300.

Zimet, G. D., Dahlem, N. W., Zimet, S. G., \& Farley, G. K. (1988). The multidimensional scale of perceived social support. Journal of Personality Assessment, 52(1), 30-41. 